\title{
New LED Package by Vacuum Printing Encapsulation Systems and High Reliability Transparent Liquid Type Epoxy Resin
}

Atsushi OKUNO*, Noritaka OYAMA* and Yoshiteru MIYAWAKI*

真空印刷封止システムを用いた新型LED パッケージと高信頼性の無色透明液状エポキシ樹脂

奥野 敦史*, 大山 紀隆*, 宮脇 善照*

*サンユレック株式会社半導体事業部材料開発グループ（テ569-8558大阪府高梘市道鵜町 3-5-1）

* Material Development Group, Semiconductor Department, Sanyu Rec Corporation (3-5-1 Dou-cho, Takatsuki-shi, Osaka 569-8558)

\begin{abstract}
概要 最近の表示案内盤は, LEDモジュールを利用した表示盤が多い。われわれは，このLEDモジュールのLEDレンズ工 法として真空印刷封止システム (以下，VPES ${ }^{\mathrm{TM}}$ と記す）を使用した。VPES ${ }^{\mathrm{TM}}$ は, 真空中で樹脂を印刷封止するシステムであ りこれを適用することにより軽薄短小と独特の光学特性をあつ新しいLED モジュールが完成した。また，このVPESTM に適 合した特殊な一液性無色透明のエポキシ樹脂の開発を, 硬化剂の選定と微細シリカの添加量の検証から行い, さらに透明性と 耐熱性を改善させた配合物に改良することができた。
\end{abstract}

Key Words: LED (Light Emitting Diode), VPES ${ }^{T M}$ (Vacuum Printing Encapsulation Systems), Thixotropic Index, Refraction Index, Liquid Epoxy Resin

\section{Introduction}

Recently manufacturing of high brightness blue LED devices, which was thought to be difficult, reached practical level. Now three primary colors of light (Red, Green, Blue) are available for high brightness LED. As a result, applications of LED have expanded, from indoor to outdoor, single color to multi colors and text display to image display.

In addition, combining blue LED device and YAG (Yttrium Aluminum Garnet) phosphor for creating white color is attracting many attentions, for white LED can be used in lighting and automotive applications $^{1)}$. It is certain that LED applications will further expand. Furthermore, in order to improve LED functionality, high-density integration, thin and lightweight, mass production capability, low cost and improved speed for LED will be necessary.

We have been proving that our new packaging method, PES ${ }^{\mathrm{TM}}$ (Printing Encapsulation System) is superior than transfer molding method in terms of highdensity integration, thin and light weight, mass production capability, low cost and improved speed in applications such as COB, BGA, CSP, TAB, Flip-Chip, MCM, Wafer level CSP and Stacked $I^{2) \sim 4)}$. Then we applied Vacuum Printing Encapsulation System $\left(\mathrm{VPES}^{\mathrm{TM}}\right)$ to solve air bubble problems ${ }^{5)}$.

In this paper, we will explain about epoxy resin (relation of thixotropic agent and LED lens shape and transparency of this resin after encapsulation process), which is suitable for LED packaging using this VPES ${ }^{\mathrm{TM}}$ method.

\section{Method of LED Packaging}

Encapsulation process of epoxy resin protects LED chip and gold wire from air and moisture and effectively take out light emitted from chip at the same time (It enhances efficiency of take out). For this reason, encapsulation process is very important in terms of enhancement of LED optical characteristics.

\subsection{Casting Method}

Casting method is a typical method for LED lamp packaging. The process die-bonds LED device to mirror within lead-frame. Then LED device and leadframe are wire-bonded. Low viscosity epoxy resin is put into the mold and packaged lead-frame is put into the mold for de-airing. After the process, curing takes place $^{6)}$.

Recently LED application expanded to a collective lamp consisting of many LED lamps and LED dot matrix modules. However cannonball shaped lamps require soldering of each lamp on substrate. It is quite difficult to align them neatly. In addition, this soldering process makes module heavier and thicker. This has a negative effect if many modules are used in the final stage, resulting in heavy total weight and increased thickness. There is a way to make them thin and light weight and highly integrated using $C O B$ 
technology (method using reflection board and diffusion sheet instead of lens). Yet, chip does not have epoxy resin over it, making it darker than LED lamps typically.

If dispenser method is used on this COB type LED chip for encapsulation of epoxy resin, it takes quite a bit of time to dispense resin. If a $16 \times 16=256$ dot LED dot matrix type module is encapsulated with automatic dispenser, it takes about 600 seconds to encapsulate the entire module. At the same time, uniformity of lens thickness is not guaranteed. This method is not clearly suitable for mass production clearly.

\subsection{VPES $^{\mathrm{TM}}$}

We have been developing printing encapsulation technology for COB. As a result, by using $\mathrm{PES}^{\mathrm{TM}}$ method shown in Fig. 1, we successfully solved those problems. The operation efficiency of $\mathrm{PES}^{\mathrm{TM}}$ is better

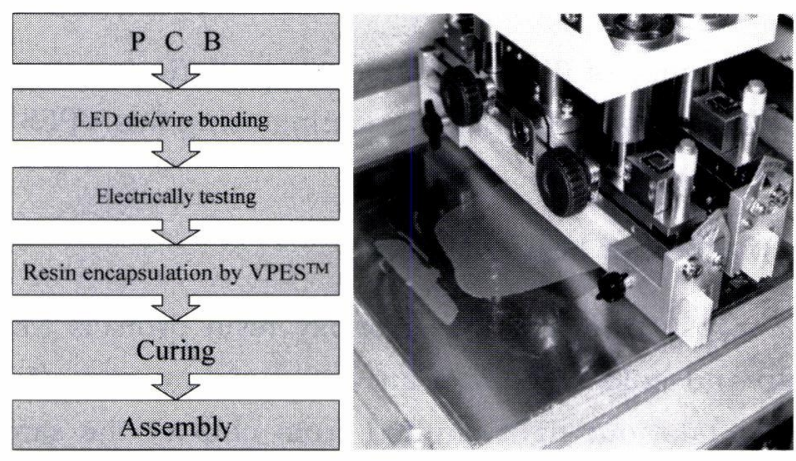

Fig. 1 New LED package process of VPES ${ }^{\mathrm{TM}}$ and Printing condition than that of dispenser method.

However, there are air bubbles in encapsulated epoxy resin. Because of this, it was necessary to add de-air process and it was necessary to compensate defect portion of LED lens (Fig. 2). In order to solve those problems, VPES ${ }^{\mathrm{TM}}$ method was developed. Principal theory of VPES ${ }^{\mathrm{TM}}$ is that vacuum chamber having PES $^{\mathrm{TM}}$ mechanism inside (Fig. 3). Because of this feature, air bubbles in epoxy resin are minimized. As VPES $^{\mathrm{TM}}$ prints in vacuum, de-air process is not necessary. And time required for compensation was reduced dramatically. Total process time of $\mathrm{VPES}^{\mathrm{TM}}$ is shorter than PES $^{\mathrm{TM}}$ (Fig. 4).

COB packages are more suitable for fine pitch applications than lead frame type. In addition, elimination of soldering process contributes dramatic reduction of operation time. Cleaning process after soldering is not necessary, being environmentally friendly. When a $16 \times 16=256$ dot matrix module is encapsulated with VPES $^{\mathrm{TM}}$, there is no deformation of gold wire and encapsulation completes in about 1 minute. This proves that VPES ${ }^{\mathrm{TM}}$ is more suitable in mass production capability than dispensing method. LED thickness is determined by mask thickness. Therefore, controlling of thinness is possible with VPES ${ }^{\mathrm{TM}}$. VPES $^{\mathrm{TM}}$ is the most effective in new type of LED packaging. Comparison data between conventional type (cannonball type) and new type is shown in Fig. 5.

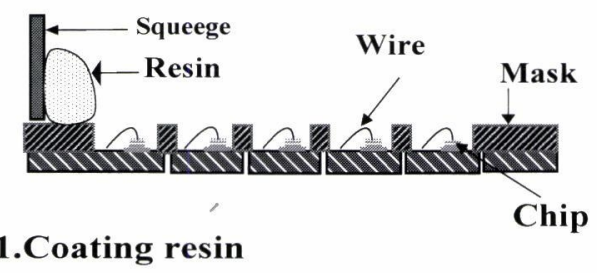

\section{PCB is down with table.}

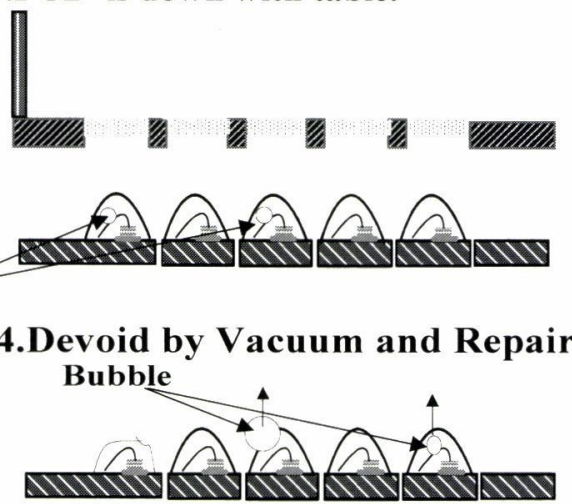

2.Printing for clean

5.Complention
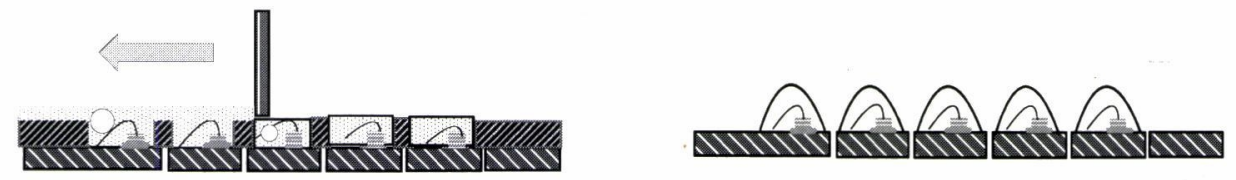

Fig. 2 Process of PES ${ }^{\mathrm{TM}}$ 


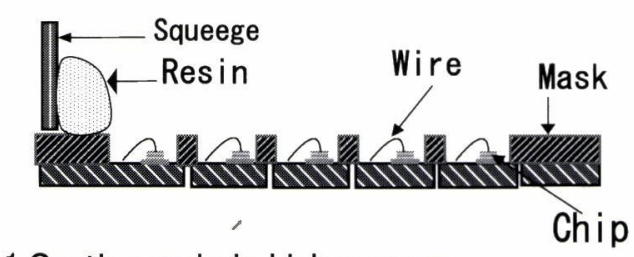

1.Coating resin in high vacuum
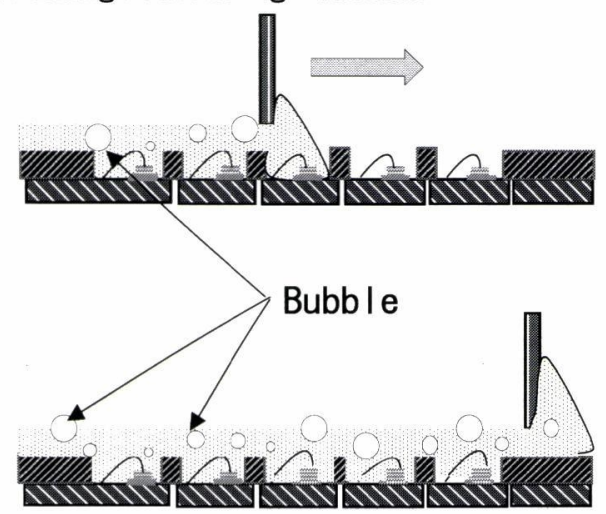

\section{Entering resin hole of Mask}

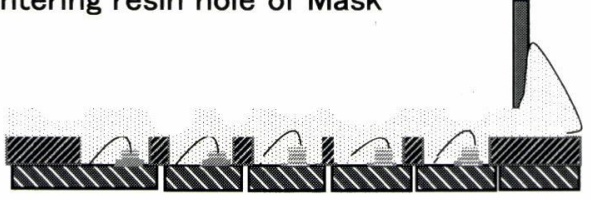

3.Printing for clean

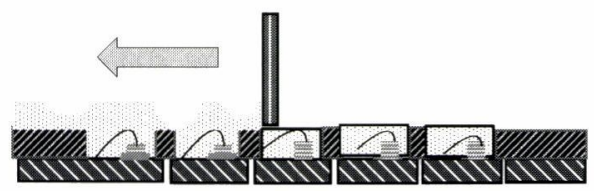

4.Complention

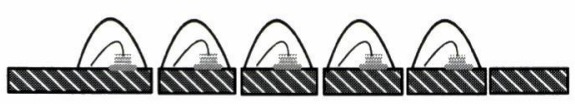

Fig. 3 Process of VPES ${ }^{\mathrm{TM}}$

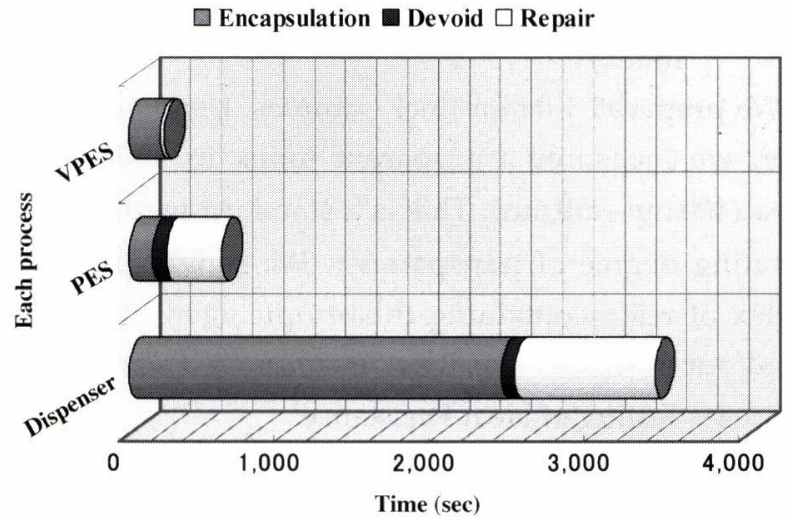

Fig. 4 Compare of process time Dispenser method, $\mathrm{PES}^{\mathrm{TM}}$ and VPES ${ }^{\mathrm{TM}}$

\section{Liquid Epoxy Resin for VPES ${ }^{\mathrm{TM}}$}

Epoxy resin used for $\mathrm{VPES}^{\mathrm{TM}}$ has to be suitable for printing. The newly developed epoxy resin forms LED lens by surface tension of resin and cures quickly by heat. However, heat curing typically reduces viscosity of epoxy resin drastically and it makes resin to easily flow on PCB. In another word, it leads to collapse of LED lens formation. For this reason, we used thixotropic agent to control fluidity of resin on PCB. However, more quantity of thixotropic agent is contained, transparency of epoxy resin is lost. We used acid anhydride for curing agent as epoxy resin for typical LED ${ }^{7}$. However, it has short pot life and shelf life. In addition, compounded material of acid anhydride has very low viscosity. Furthermore, it has to fulfill re-

\begin{tabular}{|c|c|c|c|c|}
\hline Series & \multicolumn{2}{|c|}{ Formal Technology } & \multicolumn{2}{|c|}{ Our Technology } \\
\hline \multicolumn{5}{|l|}{$\begin{array}{c}\text { Cross Section } \\
\text { Photograph }\end{array}$} \\
\hline Dot member & \multicolumn{2}{|c|}{$16 \times 16(256)$} & \multicolumn{2}{|c|}{$24 \times 24(576)$} \\
\hline Lens Thickness & \multicolumn{2}{|c|}{$10.0 \mathrm{~mm}$} & \multicolumn{2}{|c|}{$0.8 \mathrm{~mm}$} \\
\hline \multirow{2}{*}{$\begin{array}{c}\text { Encapsulated } \\
\text { Area(Lens Area) }\end{array}$} & Pitch space & $6.0 \mathrm{~mm}$ & Pitch space & $4.0 \mathrm{~mm}$ \\
\hline & Diameter & $4.0 \mathrm{~mm}$ & Diameter & $3.2 \mathrm{~mm}$ \\
\hline Board Thickness & \multicolumn{2}{|c|}{$9.0 \mathrm{~mm}$} & \multicolumn{2}{|c|}{$1.2 \mathrm{~mm}$} \\
\hline Total Thickness & \multicolumn{2}{|c|}{$22.0 \mathrm{~mm}$} & \multicolumn{2}{|c|}{$6.0 \mathrm{~mm}$} \\
\hline
\end{tabular}

Fig. 5 Comparison to formal technology

liability of LED. The detailed requirements are listed below.

(1) It has to have long pot life so that resin viscosity does not change dramatically during printing operation

(2) It has to maintain thixotropic index, in another word, it has to be able to form LED lens

(3) It has to be transparent resin

(4) It has to be heat resistant

We searched new curing agent and developed new epoxy resin to fulfill above requirements. 


\subsection{Testing of Epoxy Encapsulation Resin for VPES $^{\mathrm{TM}}$}

\subsubsection{Testing of Thixotropic Index}

We use bis-phenol type epoxy resin as base epoxy, special new curing agent, and thixotropic agent for controlling thixotropic index of $\mathrm{VPES}^{\mathrm{TM}}$ resin. The thixotropic agent is high purity silica powder, which is less than 10 micron in diameter, having $200-400 \mathrm{~m}^{2} / \mathrm{g}$ high specific surface area and more than $99.9 \%$ purity. Our sample is manufactured by combining the materials mentioned above.

For Comparison of samples, we used anhydride for curing agent, fourth phoshonium for the accelerator and other materials same with our original sample. These comparison samples are same as conventional products, which are used as typical resins for LED. First we put those samples in glass containers and left them in a bath of water, which is kept at $23^{\circ} \mathrm{C}$. After some time, we measured viscosity of sample resins. We plotted relationship of added amount of thixotropic agent and viscosity conditions. Temperature is $23^{\circ} \mathrm{C}$. Viscosity is at $20 \mathrm{rev} / \mathrm{min}$ of viscosity measure. Thixotropic index is calculated with the following equation.

$$
\mathrm{TI}=\eta_{2} / \eta_{1}
$$

where $\eta_{1}$ is viscosity in $20 \mathrm{rev} / \mathrm{min}$ and $\eta_{2}$ is viscosity in $2 \mathrm{rev} / \mathrm{min}$.

Simultaneously, to prove our point for necessity of adding thixotropic agent, we prepared cured samples that contain thixotropic agent (types with 3 percent and 5 percent mixed in) and one does not contain thixotropic agent and we measured and compared spreading and height.

We also prepared acid anhydride as curing agent (conventional product) and our new special curing agent (our proprietary sample) and compared correlation. The measurement method using our own definitions is explained below.

As standard experiment, first we drew a $3.0 \mathrm{~mm}$ diameter circle on PCB and potted $0.01 \mathrm{~g}$ sample resin inside the circle. Potting is made to shape dome representing LED shape. Potted resin is then cured. (Curing condition: $100^{\circ} \mathrm{C} / 2$ hours $+150^{\circ} \mathrm{C} / 2$ hours )

〈Measurement of spreading

We used surface coarseness measuring equipment to measure spreading of dot diameter of the cured samples. We measured five dots for each type from the entire samples and obtained averages. Degree of spread- ing is calculated by using the following definition.

$\mathrm{B}=\left(\mathrm{D}_{1}-3.0\right) / 3.0$

$\mathrm{D}_{1}$ is diameter of a cured sample.

3.0 is diameter of the initial circle.

$<$ Measurement of Height $>$

We used micrometer to measure dot height of each cured sample. Similarly to spreading measurement, we measured five dots for each type from the entire samples and obtained averages.

\subsubsection{Testing of Pot Life}

Pot life by our definition means stability of viscosity as single liquid epoxy resin will have degradation of viscosity as time passes sooner or later. We performed comparison testing of curing agent based on acid anhydride, which is used in conventional products and special curing agent used in our samples. The result is shown in comparison plotting of pot life period and viscosity for both samples.

\subsubsection{Testing of Transparency (Testing of Transparent} Index)

We prepared $1.0 \mathrm{~mm}$ thick samples. Using spectrometer, we measured transparent index in visible light area $(400 \mathrm{~nm}-950 \mathrm{~nm})$. This is a standard method of indicating degree of transparency. We show transparent index of resin containing thixotropic agent. We measured our samples as well as our improved samples.

\subsubsection{Testing of Heat Resistance}

We proved thermal degradation of transparent index at $150^{\circ} \mathrm{C} / 20$ hours later and at $180^{\circ} \mathrm{C} / 20$ hours later. We measured transparent index in wavelength of blue color area $(450 \mathrm{~nm})$. We also confirmed external appearances. Similarly to testing of transparency, we measured our samples as well as our improved samples.

\subsection{Results and Thoughts}

\subsubsection{Testing of Thixotropic Index}

Figure 6 shows result of viscosity change by added amount of thixotropic agent and thixotropic index. The result indicates a small amount of silica powder yields 3.0 and greater thixotropic index. We will explain why small amount of high purity silica powder results in reasonable thixotropic index.

First, surface of silica is soaked with $\mathrm{SiOH}$. $\mathrm{SiOH}$ on silica surface tends to bond by hydrogen bonding. Each silica powder forms chain structure or network structure independently. However, this hydrogen bonding is relatively weak bonding. For this reason, applying small energy will disassemble them. At that 


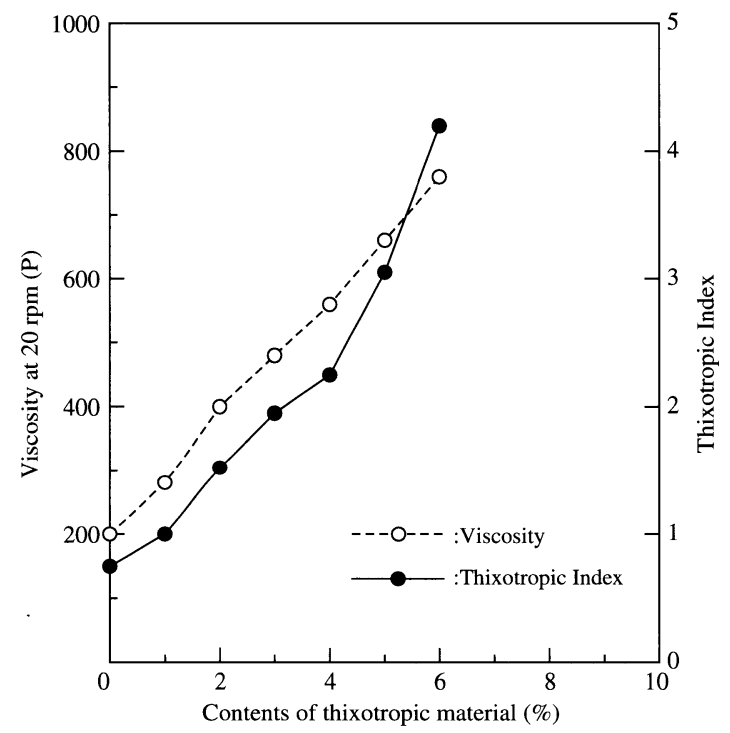

Fig. 6 Relation of viscosity,thixotropic index and contents of thixotropic agents in our sample

time, viscosity of resin becomes low.

When this energy is removed, silica powder rebonds. In another word, this phenomenon is thixotropic phenomenon (Fig. 7). By keeping temperature at stable storage condition, thixotropic index can be maintained relatively stable ${ }^{9) \sim 11)}$.

As for spread of LED lens (curing sample), we found out that as thixotropic index increases, spread becomes smaller. However, if we kept amount of thixotropic agent the same and used conventional product having acid anhydride as curing agent, its spread was larger than our proprietary samples (Fig. 8). This is because, even with curing activation agent, acid anhydride has relatively slow reaction to heat. In another word, even with added thixotropic agent, thixotropic effect becomes smaller due to heat. Because of this, in order to maintain shapes of LED lens, we have to use a curing agent, which will cure quickly with application of heat.

\begin{tabular}{|c|c|c|c|c|c|c|c|}
\hline \multicolumn{4}{|c|}{$<$ Our sample> } & \multicolumn{4}{|c|}{$\begin{array}{l}<\text { Type of acid anhydride }> \\
\text { Unit:mm) }\end{array}$} \\
\hline & $0 \%$ & $3 \%$ & $5 \%$ & & $0 \%$ & $3 \%$ & $5 \%$ \\
\hline 1 & 133 & 37 & 8 & 1 & 233 & 153 & 116 \\
\hline 2 & 120 & 40 & 7 & 2 & 216 & 160 & 120 \\
\hline 3 & 116 & 33 & 7 & 3 & 190 & 150 & 120 \\
\hline 4 & 133 & 35 & 7 & 4 & 216 & 166 & 126 \\
\hline 5 & 126 & 40 & 6 & 5 & 233 & 170 & 120 \\
\hline Ave. & 126 & 37 & 7 & Ave. & 218 & 160 & 120 \\
\hline \multicolumn{8}{|c|}{ Height of LED lens (Unit:mm) } \\
\hline & $0 \%$ & $3 \%$ & $5 \%$ & & $0 \%$ & $3 \%$ & $5 \%$ \\
\hline 1 & 0.1 & 0.3 & 0.8 & 1 & - & 0.05 & 0.2 \\
\hline 2 & 0.2 & 0.4 & 0.75 & 2 & - & 0.1 & 0.15 \\
\hline 3 & 0.05 & $\begin{array}{l}0.55 \\
\end{array}$ & 0.7 & 3 & 0.05 & 0.05 & 0.2 \\
\hline 4 & 0.1 & 0.35 & 0.7 & 4 & - & 0.05 & 0.1 \\
\hline 5 & 0.15 & 0.4 & 0.7 & 5 & - & 0.1 & 0.2 \\
\hline Ave. & 0.12 & 0.4 & 0.73 & Ave. & - & 0.07 & 0.17 \\
\hline
\end{tabular}

Fig. 8 Relation of spread, height and contents of thixotropic agents

\subsubsection{Testing of Pot Life}

As shown in Fig. 9, traditional resins for LED (resin, which uses acid anhydride as curing agent) have a short pot life. For this reason, this type of resin changes its viscosity every day. If we would like to use this resin, we have to change printing conditions for each day, making it unsuitable for printing.

On the other hand, pot life of our samples, maintains relatively stable viscosity even for seven days. Similarly for thixotropic index, it is maintained stable. Because of this, LED lens can be manufactured using this material, while maintaining stable shapes. Use of acid anhydride as curing agent is because it is known to have relatively superior characteristics (electrical, mechanical and chemical) for LED application. However, adding of curing accelerator and moisture tends to cause ring opening, later causing relation with epoxy resin. For this reason, its viscosity rises very quickly.

On the other hand, the aromatic sulfonium as curing agent, which was in our proprietary sample, is stable

(2)Chained particles

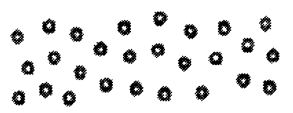

(3)Agglomerated chained particles

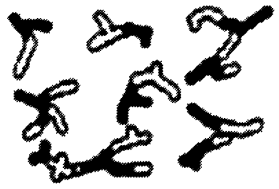

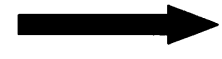

(4)Three-dimensional structure

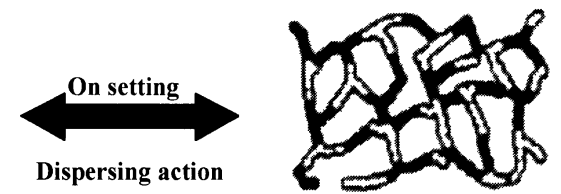

Fig. 7 Schematic representation of the interaction between super small particles ${ }^{8)}$ 


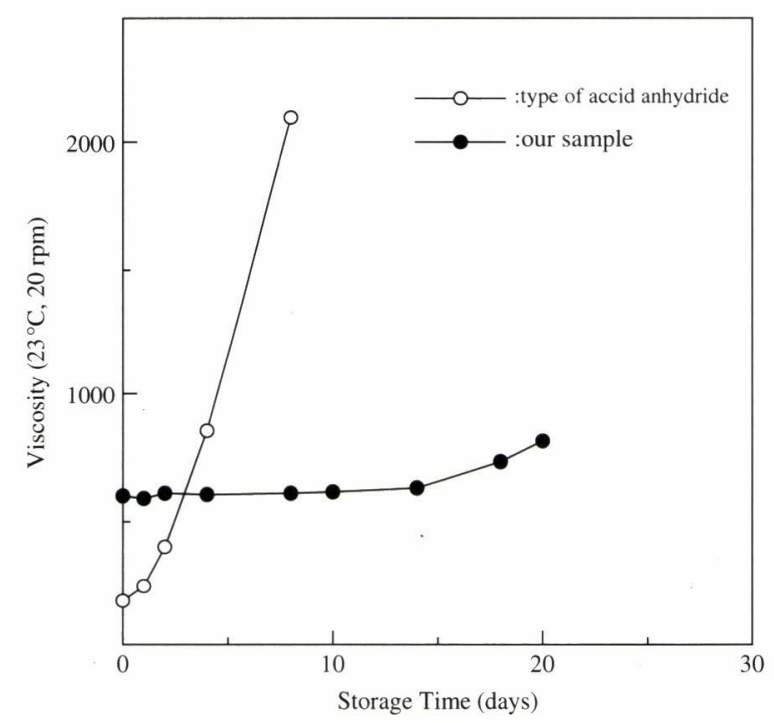

Fig. 9 Viscosity changing of each resin sample

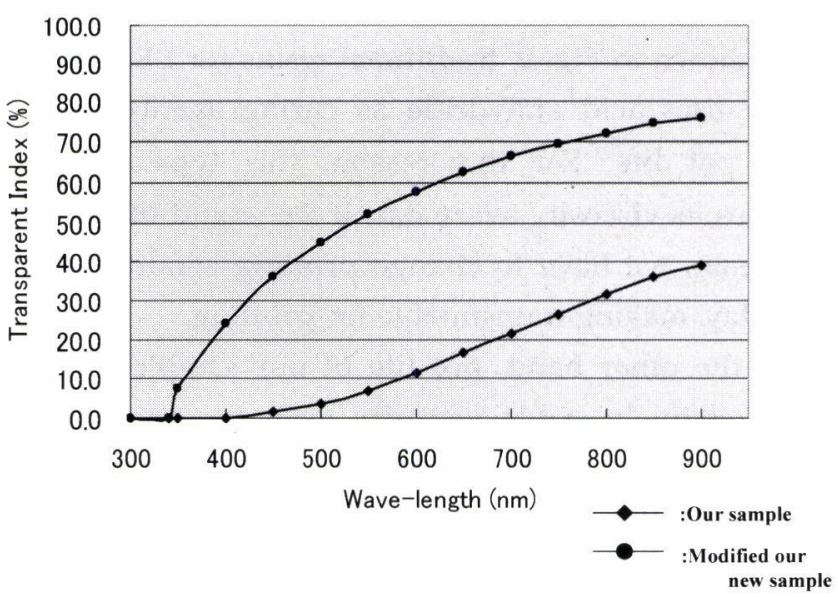

Fig. 10 Comparison of both sample's transparent Index

at room temperature and characterized by latent effect of being quickly cured with heat application, leading to the shown result.

\subsubsection{Testing of Transparency (Testing of Transparent Index)}

Figure 10 is data for transparent index. Our samples look little clouding as there is a difference between refractive index of the base epoxy resin and refractive index of the thixotropic agent, leading to deterioration of transparent index. We revised refractive index of our base epoxy resin so that it will be close to refractive index of the thixotropic agent. As it is shown in Fig. 10, transparent index of our revised samples improved. The revised epoxy resin is even more transparent than our previous one.

\subsubsection{Testing of Heat Resistance}

Figure 11 shows external view after heat resistance test $\left(150^{\circ} \mathrm{C} / 20\right.$ hours and $180^{\circ} \mathrm{C} / 20$ hours) and transparent index at blue color wavelength area $(450 \mathrm{~nm})$,

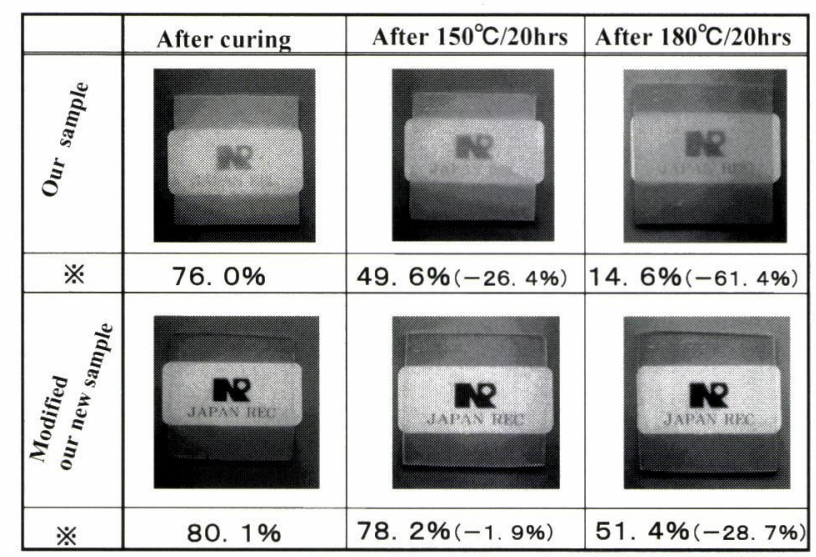

※The number are transparent rate in the wavelength of $450 \mathrm{~nm}$.

Fig. 11 Deterioration of appearance and transparent index after each heat resistance test

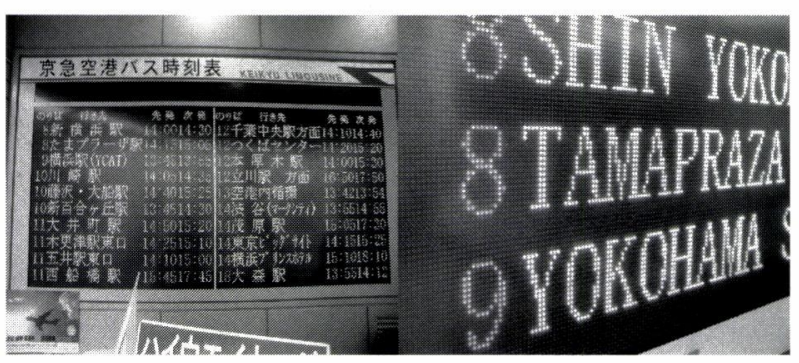

$<$ Message board of Bus station $>$

Fig. 12 Illustration of LED package by VPES ${ }^{\mathrm{TM}}$

where it is typically difficult for light to pass through, and degree of deterioration from the initial stage. In another word, drastic heat causes change in the curing agent, leading to deterioration of transparent index. The result shows that our samples did have issues with heat resistance, however, our new samples with the improved resin did not change color much. This means that this can be used for portions that have direct contact with blue LED (for being kept lit for some time, it is said to rise to about $120^{\circ} \mathrm{C}$ ). In addition to improvement in transparent index, we could obtain good result in heat resistance.

\section{Concluding Remarks}

We successfully transferred from casting method to VPES $^{\mathrm{TM}}$ method and successfully develop new resin. We believe that combination of VPES ${ }^{\mathrm{TM}}$ and our special transparent epoxy resin will be suitable for highdensity integration, thin and light-weight format, mass production capability and reducing cost. This combination has been used in various LED display devices (Fig. 12). We believe we will have much demand from the LED industry for our system in the future.

(2003.4.9-受理) 


\section{References}

1) I. Akasaki: "The Fascination of Blue LED Device", pp. 151-156, Kogyochosakai, May, 1997

2) A. Okuno, et al.: "New Packaging of Chip on Board by Unique Printing Method", Proc. IEEE 41th Electronic Components \& Technology Conf. Atlanta, USA, pp. 843847, May, 1991

3) A. Okuno, et al.: "Printing Encapsulation Systems (PES) of Advanced Multi Chip Module \& COB Device", Proc. IEEE 42th Electronic Components \& Technology Conf. San Diego, USA, pp. 783-786, May, 1992

4) A. Okuno, et al.: "Method of Sealing Electric Parts Mounted on Electric Wiring Board with Resin Composition", US P 5,232,651. Dec., 1990

5) A. Okuno: "High Reliability, High Density, Low Cost Packaging Systems for Matrix BGA \& CSP Using VPES (Vacuum Printing Encapsulation Systems)", $48^{\text {th }}$ Elec- tronic Components \& Technology Conference, p. 109, May, 1998

6) Y. Okuno: "Light Emitting Daiode", pp. 105-113, Sangyotosho, Jan., 1993

7) T. Shiohara, et al.: “Opto Transparent Epoxy Resin Composite and Opto Semiconductor Equipment", JP 2,526,740. Aug., 1992

8) S. Muroi and H. Ishimura: "The Guide EPOXY RESIN", pp. 110-112, Kobunshi Kankokai, Apr., 2002

9) A. Okuno, et al.: "The Liquid Epoxy Resin by Printing Encapsulation Systems (PES) for LSI and the Reliability of Them", The Transaction of the Institute of Electronics, Information and Communication Engineers, pp. 431-439, Sep., 1996

10) H. Lee and K. Neville: "Hand Book of Epoxy Resins", chap. 14, MacGraw-Hill, 1967

11) S. Kiriyama: "Epoxy Resin", Kobunshi Kako, p. 83, June, 1973 